\title{
Análise do Comportamento aplicada à promoção da saúde: uma revisão de escopo
}

\author{
Luiz Felipe Cruz
}

Fani Malerbi

A Análise do Comportamento, enquanto ciência descritiva e experimental, capaz de apontar as causas dos mais complexos comportamentos, oferece meios de estudar e modificar uma grande gama de problemas sociais. Entretanto, uma área de atuação pouco estudada por analistas do comportamento é a saúde pública, mais especificamente a promoção da saúde. Como uma revisão de escopo, a atual pesquisa buscou levantar o conjunto de estudos publicados em três idiomas (português, inglês e espanhol) sobre Análise do Comportamento aplicada à promoção da saúde, com o objetivo de identificar tipos de intervenção sendo utilizados, possíveis lacunas metodológicas ou conceituais e a extensão desses estudos. A pesquisa foi realizada em cinco bases de dados: Lilacs, PubMed, ERIC, Scopus e PsycINFO. Estudos foram analisados a partir de dados bibliométricos, dados relacionados ao tipo de estudo conduzido, classes de comportamentos alvos de intervenção, população alvo e delineamentos de pesquisa. Também foram analisados em relação a critérios para avaliação de intervenções de promoção da saúde propostos pela OMS (participação social, empoderamento, equidade, sustentabilidade, ações multi-estratégicas e concepção holística de saúde). Para essa análise, foram elaborados parâmetros arbitrários, baseados em uma tentativa de operacionalização desses critérios. Oitenta e nove publicações foram analisadas. A coleta de dados indicou que a maioria dos estudos foi realizada nos Estados Unidos (89,8\%). Tipos de pesquisa com maior representação foram estudos de fatores preditores/determinantes (34,8\%), avaliação de intervenções (25,8\%) e artigos de discussão (25,8\%). Entre estudos que planejaram algum tipo de intervenção, a maioria (77\%) atingiu no máximo três dos seis critérios de avaliação da OMS. Com base nesses dados, discuto a dificuldade de operacionalizar critérios tão complexos e abrangentes e defendo o mérito dessa empreitada. Falta de clareza conceitual e teórica a respeito do que são Análise do Comportamento e promoção da saúde pode ser responsável por parte dos resultados encontrados. Por fim, concluo que a Análise do Comportamento pode ser uma ciência prestativa a iniciativas de promoção da saúde por meio de esforços para operacionalizar objetivos e ajudar a planejar intervenções e sua implementação. 